\title{
Representaciones de la infancia en el espacio de las historietas, 1900-1980
}

\author{
JORGE ROJAS FLORES ${ }^{1}$ \\ 1. Doctor en Historia, Docente Universidades Alberto Hurtado, Arcis y Católica de Chile.
}

\section{Introducción}

Últimamente las historietas han comenzado a ser consideradas documentos históricos privilegiados para mostrar la forma en que circulan ideas, prejuicios y creencias en la población que accede a ellas. En su época de mayor circulación, estaban enfocadas a públicos masivos, y por su intermedio es posible identificar contenidos conscientes (en el caso de los cómics políticos y de inspiración moral) y otros que circulaban de un modo menos intencionado ${ }^{1-4}$. A diferencia de la prensa o los discursos políticos, la peculiaridad del cómic es su lenguaje, que integra imagen y texto, lo que requiere poner atención a ambas dimensiones ${ }^{5,6}$.

Si seguimos el contenido de las historietas a lo largo del tiempo, podremos ver en ellas varias formas en que se representaba la infancia. Aunque no siempre hay coincidencia en el modo en que se muestra a niños y niñas en series educativas o bien de entretención, como protagonistas o personajes secundarios, el registro da una muestra de los cambios que lentamente fueron instalándose en la sociedad.

En este recorrido panorámico nos detendremos en los niños en el cómic, dejando a un lado a los personajes adultos que se comportan de forma infantil, algo que en sí mismo podría dar pie a otro artículo. La presencia infantil ha cumplido distintos objetivos, siendo a veces un modo alegórico de mostrar problemáticas del mundo adulto, y en otras ocasiones, una forma de representar lo que son o debieran ser los niños.

\section{Los primeros cómics}

La presencia del niño en el cómic norteamericano se remonta a Yellow Kid, el pequeño que oficiaba de personaje principal de la sección "Hogan's Alley" (el Callejón de Hogan), publicado inicialmente en el New York World. En este caso, tanto Yellow Kid como los restantes pequeños que abundaban en esta serie no tienen nada de cándidos. Con rostros grotescos y sumidos en la pobreza, el sentido de cada episodio ofrece una aguda mirada de la sociedad norteamericana, sobre todo en las grandes ciudades de inicios del siglo ${ }^{7}$ (figura 1).

Casi en forma simultánea en 1897 apareció The Katzenjammer Kids, creado por Rudolph Dirks, que en Chile fue conocido como "El Capitán y los Pilluelos". Dos niños gemelos, Hans y Fritz, son el alma de esas aventuras, que desarrollan junto a sus antagonistas, el Capitán y el Inspector, y su protectora, Mama. Esta serie se conoció tempranamente en varios países, en versiones no autorizadas. En Chile apareció en la revista Sucesos, simplificándose la trama, reducida sólo a algunos personajes. Los dos niños tienen una tendencia extrema a la trave-

Recibido el 10 de octubre de 2012, aceptado para publicación el 27 de octubre de 2012.

Correspondencia a:

Jorge Rojas Flores

E-mail: jorgerojasflores@gmail.com 


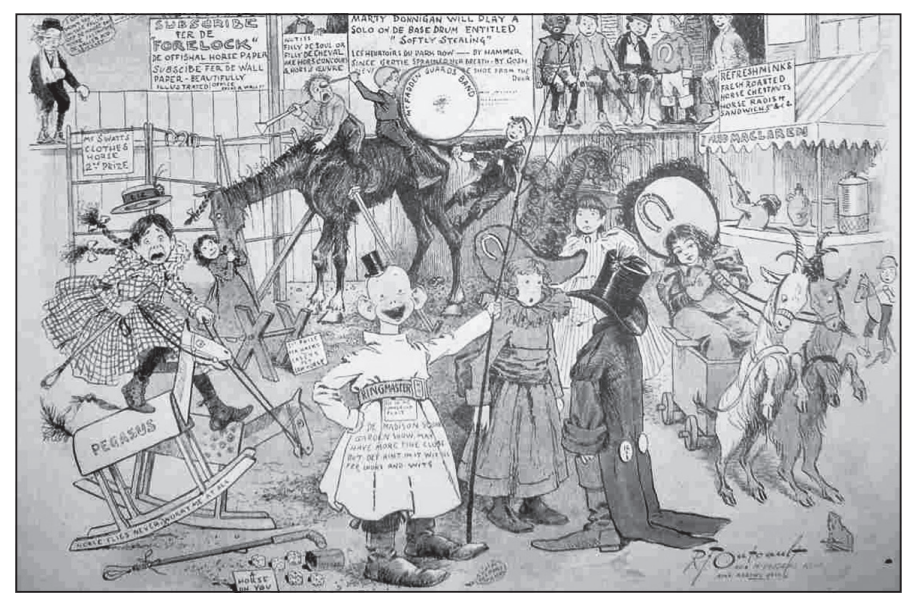

Figura 1. Detalle de Yellow Kid en New York World, 8 de noviembre de 1896. sura, siempre metiéndose en problemas, lo que indefectiblemente los hace merecedores de una fuerte reprimenda. Más adelante apareció otra versión, bajo el título de "Las aventuras de un empresario de circo", en El Peneca.

En Estados Unidos también se conocieron otros ejemplos tempranos de niños en el cómic, como "Little Nemo in Sumberland", una aventura algo surrealista enfocada en los sueños de un pequeño niño, que viaje en una tierra de fantasía ${ }^{7}$. En esos mismos años surgió la serie The Newlyweds de George McManus, concentrada en las aventuras de una pareja y su primer hijo, Snookums. Su popularidad llegó a Chile a través del cine y no, al parecer, a través del cómic ${ }^{8}$. El Pibe, el cambio, fue muy conocido, como protagonista de la película homónima de Charles Chaplin, éxito que se traspasó a sus aventuras dibujadas. Estas aparecieron en El Peneca, durante un tiempo con dibujos de Fidelicio Atria9.

En esa misma revista, dibujaba Walter Barbier y una de sus series era "La familia Levacorta", conformada por los esposos (Cirilo y Cleopatra) y sus mellizos (Tristán e Isolda) además del criado, un negrito de nombre Boby, con rasgos infantiles. Posiblemente basada en alguna historieta norteamericana, el contenido devela un claro tono racista (El Peneca, 1914).

Los diarios, a partir de 1922, comenzaron a incluir tiras cómicas. El Mercurio inició esta tendencia con "Amenidades del Diario Vivir". En esa misma década, La Unión de Valparaíso incluyó "Smitty", aunque bajo el título de
"Puntete", de Walter Berndt. Su autor se basó en su propia infancia para crear la historia. En sus inicios describe sus vivencias como vivaz ayudante en una oficina. El tono de la serie no es de denuncia contra el trabajo infantil. Al contrario, su jefe es un hombre bonachón y en sus labores el niño no deja de jugar y demostrar astucia (figura 2).

\section{La edad de oro}

En Estados Unidos, el mercado de las historietas cómicas se hizo más complejo en los años 30, con la incorporación de una mayor variedad de estilos y contenidos, como las series policiales, de suspenso, aventuras en la jungla y el oeste, ciencia ficción y superhéroes $^{7}$. En Chile, a un nivel todavía incipiente, la historieta adquirió mayor desarrollo a partir de mediados de los años 40 y 50, con la aparición de Pobre Diablo (1945), Okey (1949) y El Pingüino (1956). En estas revistas circularon no sólo creaciones chilenas, sino también extranjeras. En los diarios se hizo frecuente que aparecieran tiras diarias y suplementos semanales, como veremos más adelante.

Desde México llegaron a Chile varias versiones traducidas de clásicos norteamericanos. Uno de ellos fue "La Pequeña Lulú", creada en 1935 por Marjorie Henderson Buell. Sin ser la primera, en ella resalta el protagonismo de la niña. En los años 50, cuando al parecer llega a Chile, la trama ya gira en torno a las trave- 


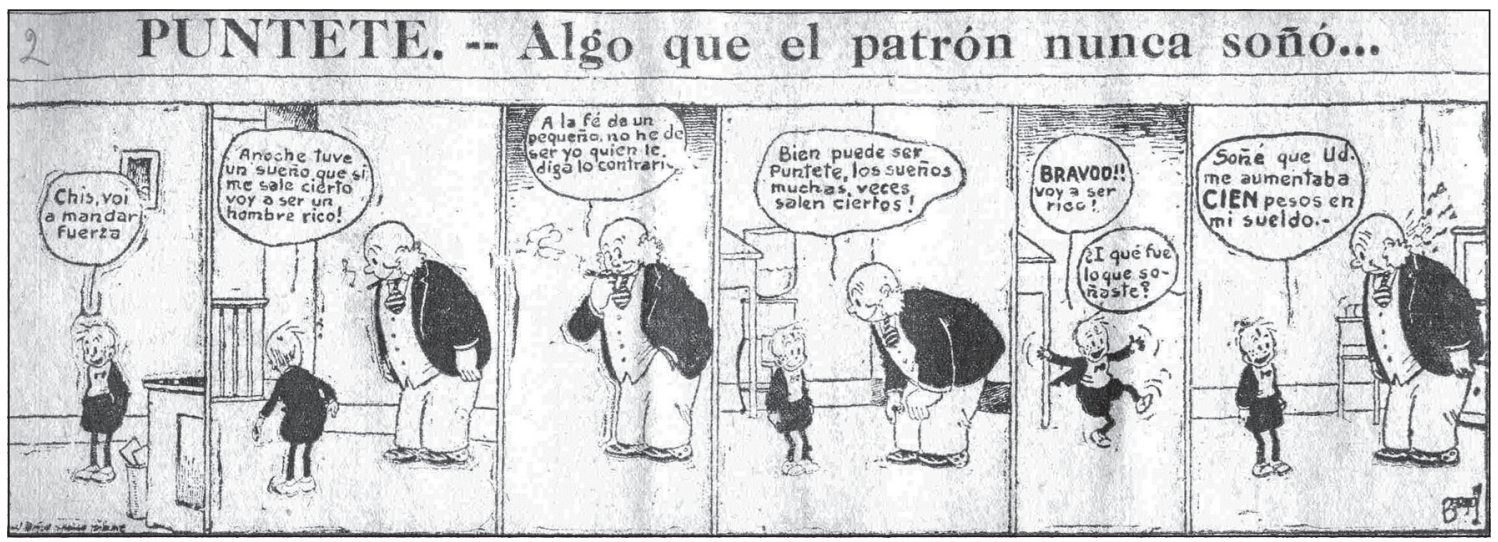

Figura 2. Puntete, en La Unión de Valparaíso, ca.1927. Colección Museo de la Historieta. Gentileza de su Director, Mauricio García.

suras de un grupo de niñas liderado por Lulú, y otro de niños, encabezado por Toby, todos entre 10 y 11 años. A veces ambos bandos (organizados en clubes, con directivas y sedes) se enfrentan, aunque sin llegar a ser realmente enemigos. De hecho, muchas veces colaboran y juegan juntos. Gran parte de las aventuras derivan del celo que existe entre niños y niñas de excluirse mutuamente en sus actividades. El contenido, en todo caso, también gira en torno a ciertos rasgos de personalidad de los diversos personajes: Anita, leal amiga de Lulú, es algo irascible; Fito, compinche de Toby, también es temperamental; Gloria, hermosa y superficial; Pepe, niño ricachón y presumido; y los Chicos del Oeste, grupo de matones y pandilleros, antagonistas de Toby, entre otros. En las sucesivas aventuras, Lulú demuestra ser bastante astuta, en ocasiones también traviesa, y generalmente termina representando el sentido común (figura 3 ).

A partir de los años 50 también se hizo conocido "Carlitos" ("Peanuts" o "Rabanitos"). En Chile apareció en la revista Periquita (editada en México) y en la tira publicada en la prensa. Con esta serie, creada por Charles Schulz en 1950, de dio inicio a un enfoque más complejo de la infancia,

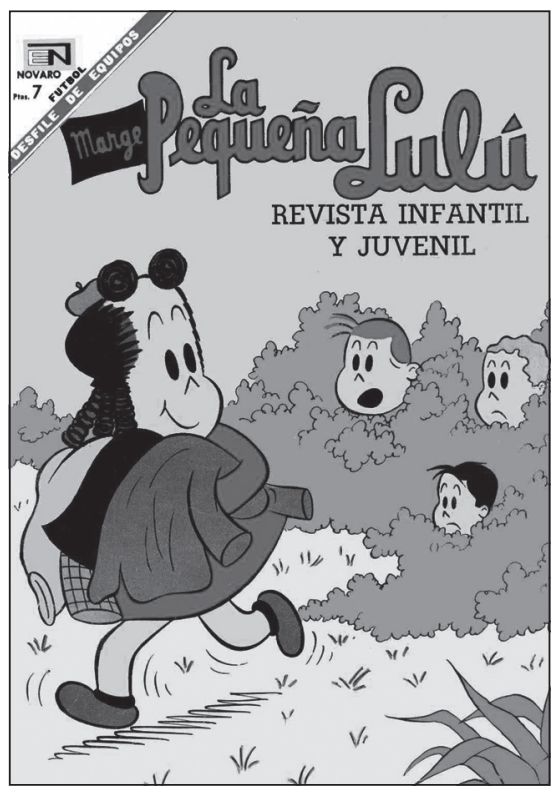

Figura 3. Travesuras de una niña ingeniosa, protagonista de $L a$ Pequeña Lulú, $\mathrm{N}^{\circ} 247$ (Novaro), 1/febr./1968.

ya que se abandonó la trama sustentada en la travesura liviana, sin mayores consecuencias, y se ahondó en las obsesiones, los temores y las preocupaciones de los niños. No fue un hecho aislado, ya que en "Lalo y Lola" (Hi and Lois), serie creada en 1954, se incursionó en el tópico del bebé que piensa.

Las clásicas travesuras infantiles no se abandonaron del todo. De hecho, "Daniel el travieso" es contemporáneo de "Carlitos". Creado en 1951, en Chile se le conoció por medio de la tira de prensa y de la versión mexicana (iniciada en 1964). Daniel es un niño inquieto y pícaro que acostumbra ensuciarse, explorar e investigar todo lo que ve. A diferencia de los niños 
que aparecen en "El capitán y los pilluelos", Daniel no es mal intencionado. Ningún adulto, además, lo castiga físicamente. A lo más su madre lo reprende obligándolo a quedarse en una esquina. Al contrario, el ambiente hogareño es de gran permisividad. Siempre sucio, con una rana en su bolsillo, trepa árboles, inventa juegos y galopa en un imaginario caba1lo, sobre la espalda de su padre. Siempre termina provocando problemas o diciendo algo que descoloca a los adultos. Margó, la niña pelirroja de reconocibles bucles, es el personaje opuesto, pulcra, ordenada y sabelotodo, que aspira a civilizar a Daniel, sin lograrlo. Henry Jenkins, estudioso del personaje, ve en esta polaridad la oposición entre dos ideales de niñez, la masculina y la femenina, completamente opuestas ${ }^{10}$ (figura 4).

Entre los artistas chilenos hubo tempranos intentos por crear personajes infantiles, aunque sin las características que hemos descrito. La mayoría tiene rasgos simples. En la revista Aladino (1949-1951), aparecen "Mapuchín", "Macuquito el inventor", "Ondita" y "Mateito". En Simbad (1949 y 1956), por su parte, Renato Andrade crea "Pelusita" y "Ponchito", ambos bastante traviesos. La primera es una niña pequeña, cuyas historias se relacionan generalmente con el hogar. Ponchito es un niño campesino, con ojotas, chupalla y una pequeña manta que le da el nombre al personaje. Uno de sus amigos es Patoco, siempre descalzo y más pobremente vestido. Sus travesuras se desarrollan en su hogar, la escuela y el campo. A diferencia de "Los Pilluelos", mencionados antes, las palizas no se hacen presente. Esto no significa que en la realidad no existan, pero han dejado de ser un recurso cómico. Las series infantiles resaltan la astucia y picardía de los niños, siempre ocurrentes.

En Chile, los niños de Barrabases (como Sam, Mono, Pirulete, Torito y varios más), revista creada en 1954 por Guido Vallejos, viven desafíos futbolísticos que tienen una fuerte carga moral, que se suma a la fuerte identidad en torno al club y en muchos casos a la selección chilena que representan. Mister Pipa, un ex jugador ya jubilado, se transforma en entrenador y transmite a sus pupilos el sentido de la amistad, el juego limpio y el esfuerzo colectivo. La trama se centra en las relaciones que surgen en torno al equipo y los socios y directivos del club, los desafíos comunes, los valores que se transmiten y las amenazas que arriesgan las enseñanzas de Mister Pipa. La revista transita por varias etapas, con algunas variantes. En la primera, entre 1954 y 1962, los protagonistas son niños pequeños, aunque en sus episodios finales sus rasgos parecen de adolescentes. En las siguientes etapas (1970-1975 y siguientes) los protagonistas actúan como niños y jóvenes, sin fronteras muy definidas. A lo largo de todas ellas, los protagonistas son varones y sólo ocasionalmente aparecen niñas, generalmente en papeles subordinados.

Aunque no se exalta el uso de la violencia, en Barrabases a veces se muestra el enfrentamiento a golpes. En un caso, los niños reaccionan con violencia cuando son agredidos por "Los palomillas", sus rivales en un partido decisivo. Como indica el nombre, estos jugadores tienen rasgos de niños malcriados o incluso de extracción marginal. Su entrenador parece un rufián y se comporta como un

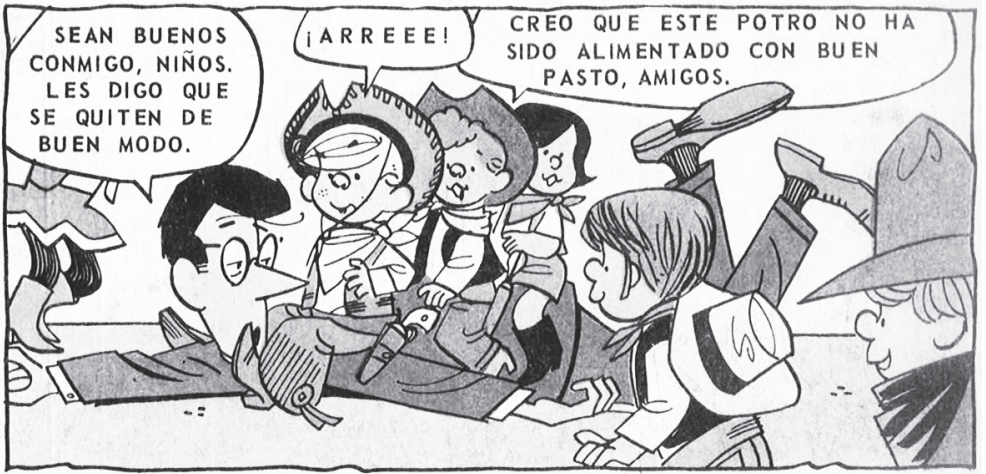

Figura 4. La permisividad en el hogar de Daniel. Daniel el Travieso, $\mathrm{N}^{\circ} 138$ (Novaro), sin fecha, ca. 1973, p. 11. 
delincuente, amenazando incluso con un arma de fuego. Trata despectivamente a los niños de Barrabases como "pitucos", en alusión quizás a una extracción social distinta ${ }^{11}$.

En esta y otras revistas, aparecen personajes infantiles creados con fines comerciales, como las aventuras de "Falabelito", "Falabelín", "Bilzito" y "Chiclito Filatélico". La infancia ya comienza a ser considerada dentro de las estrategias de mercadeo, aunque esta tendencia se profundizará a partir de la década de 1970, cuando la historieta está en declinación y comienza el auge de la televisión ${ }^{11}$.

\section{La polarización de los años 60}

Coné fue incorporado en 1967 a la serie "Condorito", como su sobrino. El personaje proviene del campo, al igual que su tío, y ha quedado huérfano. Sin mayores detalles sobre su vida anterior, siempre es representado con rasgos pícaros. Los fines morales de la trama están ausentes y en ocasiones Coné llega a colaborar en asaltos (uno de los oficios de Condorito al comienzo de la serie), aunque también asiste a la escuela. A consecuencia de alguna de sus travesuras, a veces su tío lo castiga con severidad, con golpes en el trasero que generan un sonoro llanto. Todo esto adopta un tono más bien liviano y festivo. Físicamente Coné tiene vientre abultado (algunos han sugerido una alusión a la desnutrición) y viste pantalones cortos y ropa estrecha que le deja visible el ombligo, rasgos que le dan un aspecto característico. Poco después se le agregó una amiga de aventuras, Yuyito ${ }^{11}$.

Aunque desprovista de mensajes morales, la revista Condorito elude hacer referencias a temas polémicos (aunque a veces lo hace, de modo tangencial) lo que también afecta la trama en las que el niño aparece. Esto no ocurre en "Chachito", de Mauro Cabrera, personaje que salió publicado en Ercilla (1949-1951) y brevemente en un suplemento de El Mercurio. Se trata de un bebé extrañamente precoz, que nunca se ve directamente (sólo su coche), aunque hace referencia a su interés por la bebida, el cigarrillo, las boites y la hípica. Aunque tímidamente, en esta época comienza a desdibujarse la idea de una infancia romántica, despreocupada, inocente y desprovista de problemas. Los temores y contradicciones de los adultos se reflejan en ellos.

En diciembre de 1964, también en Ercilla, aparece "Luchín y Perico", de Pepe Huinca, serie centrada en las aventuras de dos escolares de distinta extracción social, con una fuerte crítica social en su trama. Quizás por esa razón aparecieron sólo cinco episodios. Perico representa al niño pobre, descalzo, que generalmente actúa de forma más ingenua y es objeto de burlas. Luchín es un niño malicioso, que abusa de la inocencia de su amigo e incluso se apropia del poco dinero que tiene. El primer episodio se refiere al precoz despertar sexual: Luchín quiere ver a mujeres en monokini, "como la empleada cuando se ducha"; Perico dice haber visto a varias "piluchitas" y resulta que no son más que maniquíes en una vitrina.

A esta galería de personajes, se agregó Mafalda, de Quino, que comenzó a publicarse diariamente en Argentina a partir de 1964, y circuló en Chile más tardíamente en el diario Puro Chile a partir de 1970. Es probable que haya sido leída desde antes en el formato de libros compilatorios que comenzaron a salir en 1966. A gran distancia de Daniel en Travieso, Mafalda se preocupa de lo que ocurre en el mundo. La paz, la liberación femenina y la libertad son los temas recurrentes, además de los arquetipos que caracterizan a sus amigos: la avaricia capitalista de Manolito, el tradicionalismo femenino de Susanita y la simpleza de Felipe, por citar algunos.

La serie "Mampato", en la revista del mismo nombre, es el personaje infantil chileno más popular desde su aparición en 1968. Recargada de un mensaje moral y de conocimientos útiles para sus lectores, la trama transcurre en torno a diversas aventuras en el pasado o en el futuro, debido a un cinto que le permite viajar por el tiempo y el espacio. Las situaciones históricas o futuristas lo enfrentan a tiranos que oprimen al pueblo y a los efectos catastróficos de la guerra nuclear. La conciencia social (respeto a las diferencias, la armonía entre las clases sociales) y política (valoración de la democracia), así como el interés por el equilibrio ecológico se hicieron presente en esta serie ${ }^{12}$. 
Mampato es un niño que representa el modelo de infancia responsable, como hijo y estudiante, siempre respetuoso con sus padres. La relación con su hermana y sus padres siempre se muestra armoniosa. De hecho, sus aventuras transcurren en un instante (aunque la historia pareciera prolongarse varios días) lo que permite que sus padres no se alcancen a preocupar de su hijo. El peligro y el riesgo transcurren en un mundo paralelo al habitual, no en la vida cotidiana y "normal", que pareciera ser bastante rutinaria. La picardía la agrega un personaje adulto, pero con mentalidad infantil, Ogú, un cavernícola. Poco después aparece Rena, como veremos.

En pocas ocasiones, generalmente al inicio y al final de cada episodio, se muestra la vida cotidiana de Mampato. Se trata de un nexo necesario para relacionar el origen de la aventura y su desenlace, que poco afectan a la historia misma. Sólo en una ocasión la trama transcurre en la vida cotidiana de Mampato. La historia gira en torno a Rufino, un niño matón y abusador que amedrenta a algunos de sus compañeros. Mampato lo enrostra, pero el muchacho evita enfrentarse con él. Mientras los niños juegan fútbol, Rufino acusa falsamente a Carlitos de haber quebrado un vidrio con la pelota. Mampato desenmascara la mentira con su cinto espacio-temporal y el director revierte la medida. El padre de Rufino se entera de la verdad y lo castiga. Mampato comenta lo "pesada" que éste tiene la mano, mientras pasan frente a su casa y escuchan ruidos de golpes y llantos. El tono liviano del comentario, pareciera avalar el castigo físico ${ }^{11}$.

Aunque Mampato nunca es castigado de ese modo por sus padres y no hay mayores referencias al tema, el autor no participa de un modelo de crianza sustentado solamente en el diálogo o el castigo moral. En otros pasajes se insiste en justificar ciertas formas de castigo físico hacia los niños, aunque de un modo moderado. Por ejemplo, Ogú castiga a su hijo Agú, quien actúa de forma muy desobediente. Mampato le hace ver los peligros de exagerar el castigo, lo que finalmente revierte en un sentido contrario, haciendo una analogía con lo que sucede con los pueblos. La historia sirve para ilustrar lo que habría sucedido con la opresión española, que se tradujo en ansias de libertad por parte de los chilenos. Sin embargo, en otro episodio es el propio Mampato quien le da unas palmadas a Agú, nuevamente por poner en peligro su propia vida ${ }^{11}$.

\section{Los cambios en la Unidad Popular}

Las historietas no fueron ajenas a las transformaciones que acompañaron el período de la Unidad Popular. La importancia que tenían los niños en la propaganda gubernamental (basta recordar varios lemas de campaña), en la política asistencial de Allende (reparto masivo de leche, juguetes, vestuario, etc.) y en sus iniciativas educativas y culturales (Escuela Nacional Unificada, Cabrochico) llevaron a asociarlos con el discurso de la izquierda ${ }^{13}$.

Así sucedió en "Don Memorario", serie publicada en El Mercurio, donde los dos protagonistas, hombres maduros y conservadores, se ven acompañados por Juanito, un niño que juega a ser revolucionario. El "compañero" Juanito desconcierta a Don Memorario y Don Florencio, con sus denuncias de sedición o pidiendo que le compren banderitas del Mapu y del MIR para las Fiestas Patrias de 1972. En La Segunda, de la misma empresa periodística, los niños de "La familia Mengano" no son cándidos, sino precoces, al asimilar el lenguaje confrontacional de la política ${ }^{11}$.

En Cabrochico, publicada por Quimantú, la editorial estatal, la imagen de los niños adoptó un tono fuertemente clasista. Los niños pobres adquirieron especial protagonismo, a veces dando muestras de un discurso político bastante explícito, como en la serie "Estos cabros". En esa historia, un grupo de niños pobladores defiende sus derechos para jugar en una plaza. Otro cambio característico de esta revista fue la publicación de "anticuentos", versiones alternativas de los clásicos cuentos infantiles, que esperaban transmitir valores que alejaran a los niños de la influencia alienante de la literatura tradicional. El Gato con Botas, por ejemplo, miente para hacer poderoso a Pedro, su amo, pero finalmente este pone fin a la farsa, porque está cansado de tanto engaño. Blanca Nieves es una niña floja y malcriada, pero 
aprende a valorar el trabajo cuando conoce a los siete enanitos. Al final, rechaza la propuesta de matrimonio del príncipe, porque es necesario conocerse más antes de casarse ${ }^{11}$.

Uno de los enfoques que provocó polémicas en Cabrochico fue su crítica al engaño y la falsificación de la realidad. En materia sexual, por ejemplo, se da información sobre la reproducción humana, para que los padres expliquen el tema sexual. Bajo esta idea, los niños deben ser educados de manera franca, sin falsedades. Pero esto se aplica también a los relatos fantasiosos, tan comunes en la literatura infantil. Este es el tema central de "Panchito en la Tierra de la fantasía". El protagonista es un niño sano y sencillo, un pastor de ovejas, que se traslada a un mundo de fantasía. Allí, los personajes (un hada, una bruja, un ogro, un gnomo, una princesa) se sienten "seres inútiles y anormales". Su existencia se debe al mundo ficticio que ha ideado un escritor, quien busca tema para su cuento. Panchito les hace ver a todos que pueden llegar a ser útiles. Finalmente, logran transformarse en las personas que desean ser y el mundo de fantasía desaparece ${ }^{11}$.

Supercauro fue un personaje infantil emblemático de la izquierda, creado por Pepe Huinca en 1970, con ocasión de la campaña presidencial. El protagonista es un pequeño cantor de micro y lustrabotas que se convierte en un superhéroe. Para transformarse se ayuda de una sana alimentación, como la leche. Su figura es tosca, nada idealizada, para resaltar su origen humilde: boca ancha y figura esmirriada. Hay elementos de parodia a los superhéroes en los rasgos de este personaje. Sin embargo, más importante es el evidente propósito de valorar al "cabrito" de barrio, astuto y vivaz, sin más poder que la razón y su entusiasmo. Aunque el niño dice que es capaz de enfrentarse a puñetazos con sus enemigos, siempre logra vencer con argumentos y organización. De hecho, la enseñanza de la serie es que los superhéroes no son necesarios. Es suficiente la organización y el trabajo colectivo. Esto queda en evidencia en sus luchas contra el mercado negro y el acaparamiento, el analfabetismo y conspiraciones de todo tipo ${ }^{11}$ (figura 5).

En "Mampato", el niño protagonista se incorpora a aventuras donde el elemento central es la lucha por la libertad y la justicia. Además, se integra un nuevo personaje, la pequeña Rena, que termina siendo tan popular como Mampato y Ogú. Si consideramos los aspectos visuales, su figura tiene rasgos peculiares. A diferencia de otros personajes femeninos infantiles, a pesar de su corta edad (unos 10 años, al igual que Mampato) en ella hay un aire de sensualidad juvenil que probablemente contribuyó a su éxito entre los lectores. Su peinado, coquetamente ondulado, el detalle de sus labios y ojos, su diminuta minifalda y las juveniles botas provocan un evidente asociación con la estética juvenil de una "lola" adolescente y no una niña ${ }^{12}$ (figura 6).

Aunque inicialmente hay atisbos de fragilidad en Rena (en su primera aparición es rescatada por Mampato), sus poderes telepáticos le otorgan una peculiar capacidad al personaje. No son pocas las ocasiones en que ella toma el protagonismo y rescata a sus amigos, o aporta una reflexión central en la historia.

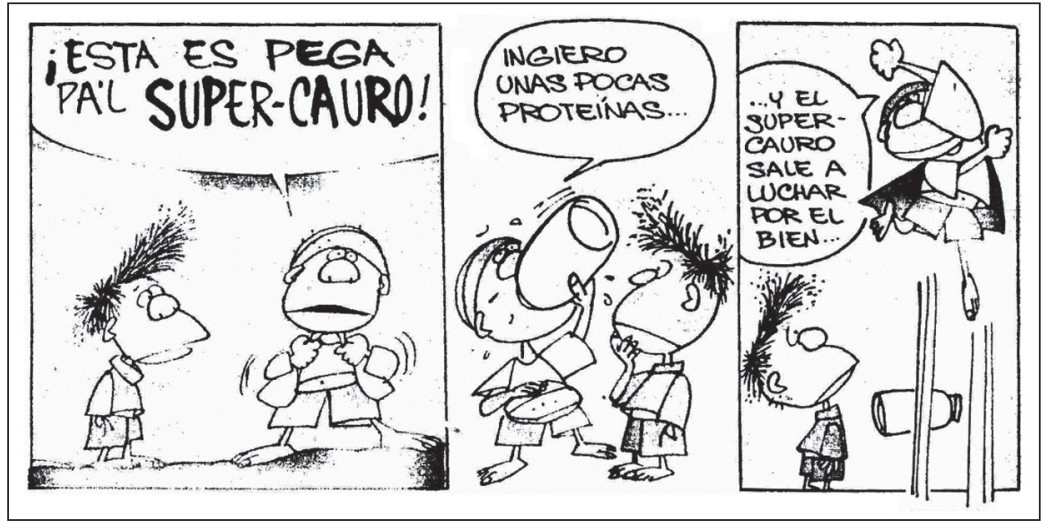

Figura 5. Supercauro, en La Firme, $\mathrm{N}^{\circ} 8$, junio/1971. 

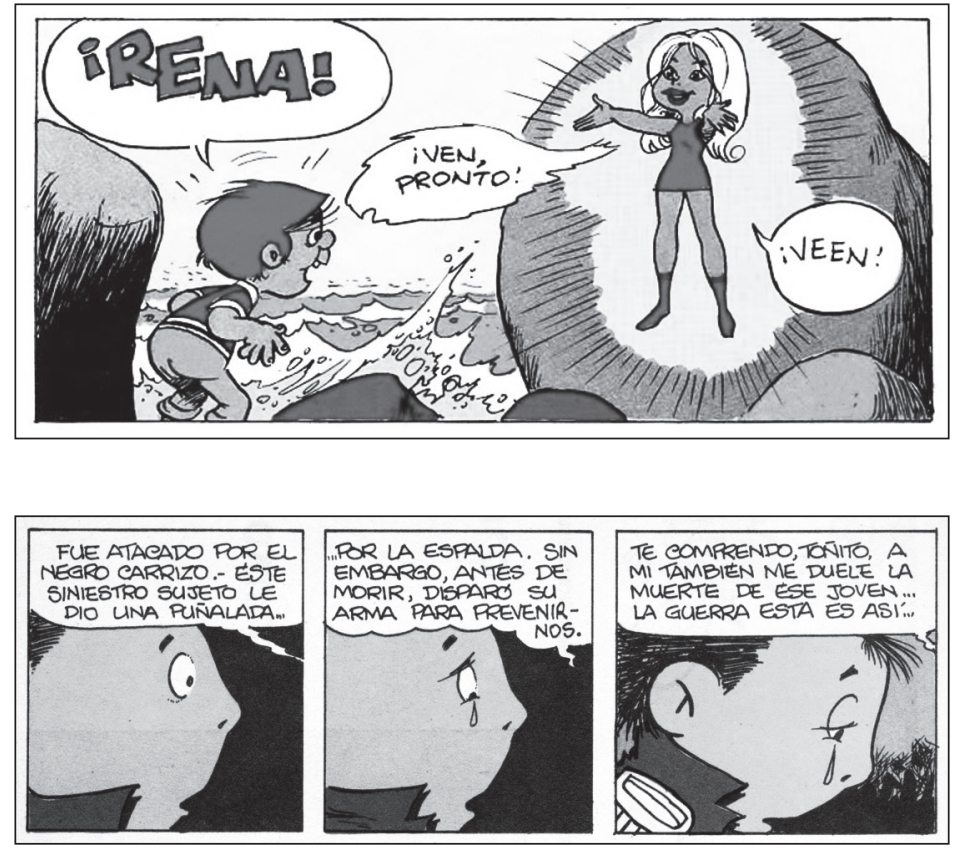

Figura 6. La sensual Rena, en Mampato, $\mathrm{N}^{\circ} 172,2 /$ mayo/1973.

Figura 7. El Capitán Toñito en un melodrama patriótico. Remolino, $\mathrm{N}^{\circ} 154,5 / \mathrm{ju}-$ nio/1977.

\section{Crisis y cambio en el ocaso de las historietas}

Tras el golpe de Estado, no sólo se produjo un cambio en el contexto político. Las transformaciones fueron más profundas y afectaron también el ámbito cultural. La influencia de la televisión se aceleró, lo que influyó sobre la historieta. Aunque siguieron circulando hasta comienzos de los 80, su presencia fue en decrecimiento $^{8,11}$.

Mampato logró sobrevivir hasta 1978. Coné se mantiene hasta hoy (incluso surgió una revista con su nombre), aunque despojado de muchos de sus rasgos originales. Sin ser un personaje preocupado de transmitir valores, con el tiempo fue asimilando un tono más ajustado a lo que se esperaba de un niño. Así como su tío había dejado de fumar, el niño pasó a ser un defensor de la ecología.

Con la crisis en la industria de revistas de historietas, fueron los diarios los que dieron cierta continuidad a la actividad. En algunos suplementos aparecieron personajes infantiles. Icarito, en el suplemento educativo del diario La Tercera, tuvo rasgos similares a Mampato en sus variadas versiones: rectitud, heroísmo y espíritu de colaboración. Sin embargo, nunca pudo igualar el mensaje político de Mampato, que se acentuó a comienzos de los 70, diluyéndose después. El capitán Toñito apareció en 1974 y fue un claro exponente de los años de Dictadura. El personaje logró exacerbar, por medio de mecanismos melodramáticos, el ambiente nacionalista de la época, a través de una trama centrada en la Guerra del Pacífico, a pocos años del centenario del acontecimiento. $\mathrm{Su}$ trágica muerte en la historia fue el fin de una serie de gran éxito, cuya interrupción en 1977 nunca se explicó completamente ${ }^{11}$ (figura 7).

A falta de otros personajes locales, Heidi se transformó en una de las más emblemáticas figuras de la infancia de fines de $\operatorname{los} 70$ y comienzos de los 80 , tanto en su versión anima$\mathrm{da}$, como en la historieta que reprodujo su historia. También de gran contenido dramático, la dulzura del personaje preservó la tradición romántica de la infancia ${ }^{11}$.

\section{Palabras finales}

Fuera de la historieta, los niños habían cambiado notoriamente cuando menos desde los años 60: su escolaridad había crecido ver- 
tiginosamente; su acceso a los medios de comunicación de masas (cine, radio, televisión) lo hacían conectarse con un mundo fuera del control paterno y de la escuela; sus hábitos cotidianos lo acercaban a la cultura juvenil.

Parte de esos cambios quedaron reflejados en las historietas, mientras otros no pudieron serlo, porque los propios adultos se resistían a aceptarlos. Un ejemplo puede ser ilustrativo de esto. Ponchito, creado en los años 40, se siguió publicando en Nuestra Tierra, una revista institucional del FUCOA, entre 1979 y 2001. Inicialmente mantuvo los rasgos originales que le dio Renato Andrade, su creador. Sin embargo, en la etapa final el dibujante debió incorporar ciertas características por presión de los administradores de la revista. Las aceptó a regañadientes, trasladando la ambientación del personaje del campo a la ciudad y cambiando el calzado, las ojotas por los zapatos y las zapatillas. Con ello se buscaba sintonizar al personaje con el niño campesino, que ya no usaba poncho ni ojotas. El siguiente paso fue eliminar el caballo y reemplazarlo por la bicicleta. El cambio fue excesivo y Nato prefirió no seguir con su personaje en la revista ${ }^{14,15}$.

El fin de la cultura agraria tradicional, producto de la Reforma Agraria de los años 60 y culminada trágicamente por Pinochet en los 80, había significado el fin de la infancia campesina que Nato había conocido. Otros cambios operaron simultáneamente y de modo muy intenso, en pocos años. La declinación del cómic chileno impidió que esto quedara reflejado en los pocos personajes infantiles sobrevivientes. En otros países, donde la historieta no sufrió con la misma intensidad esta crisis, los problemas sociales siguieron siendo mostrados bajo la mirada de un niño, como ocurrió con Calvin, de "Calvin y Hobbes" de Bill Watterson. En Chile, tardíamente se ha iniciado ese camino, con "Las Bicharracas" de Sol Díaz, por citar un ejemplo interesante. En ella, tres niñas afectadas por los cánones de belleza predominantes (una es "fea", la otra, "negra" y la tercera, "peluda") se resisten como pueden a la discriminación y a sus propios prejuicios.

\section{Referencias}

1.- Dorfman A, Armand M: Para leer al Pato Donald, Ediciones Universitarias de Valparaíso, Valparaíso, 1971.

2.- Berger A: The Comic-Stripped American. What Dick Tracy, Blondie, Daddy Warbucks, and Charlie Brown tell us about ourselves, Penguin Books, Baltimore, 1974.

3.- Steimberg O: Leyendo historietas. Estilos y sentidos en un 'arte menor', Ediciones Nueva Visión, Buenos Aires, 1977.

4.- Barker M: Comics: ideology, power an the critics, Manchester University Press, Manchester/New York, 1989.

5.- Barbieri D: Los lenguajes del cómic, Ediciones Paidos, Barcelona, 1993.

6.- McCloud S: Understanding Comics: The Invisible Art, Kitchen Sink Press, 1993.

7.- Coma J: Del gato félix al gato Fritz. Historia de los cómics. Gustavo Gili, Barcelona, 1979.

8.- Rojas Flores J, Rojas Flores G: "Auditores, lectores, televidentes y espectadores. Chile mediatizado. 19731990” en Rafael Sagredo y Cristián Gazmuri (comp.), Historia de la vida privada en Chile, vol. 3, Taurus, Santiago, 2007, págs. 381-424.

9.- García M: "100 años de "El Peneca" (1 Parte), disponible en: http://ergocomics.cl/wp/2008/05/100-años-deel-peneca-1-parte-2/

10.- Jenkins H: "Dennis the menace, "The all-american handful'", en Lynn Spigel y Michael Curtin (eds.), The revolution wasn't televised. Sixties television and social conflict, AFI Films Reader, Routledge, London, 1997, pp. 119-35.

11.- Rojas Flores J: Las historietas en Chile, 1960-1980. Industria, discursos y prácticas sociales, Santiago, tesis para optar al Grado de Doctor en Estudios Americanos, Mención Historia, Facultad de Humanidades, Universidad de Santiago de Chile, 2012.

12.- Rojas Flores J: "Estrategias de poder y valores políticos en Mampato (1968-1978)", en Mapocho, №71, primer semestre/2012., pp. 297-314.

13.- Rojas Flores J: Historia de la infancia en el Chile republicano, 1810-2010, Junta Nacional de Jardines Infantiles, Santiago, 2010.

14.- Andrade C, Montealegre J: Nato, la sonrisa imborrable, Ediciones Asterión, Santiago, 2012.

15.- Entrevista a Claudia Andrade, hija del autor del personaje, Renato Andrade. 